\title{
Healthy workplaces: what we know and what else we need to know
}

\author{
Jensen, Per Anker; van der Voordt, Theo
}

Published in:

Journal of Corporate Real Estate

Link to article, DOI:

10.1108/JCRE-11-2018-0045

Publication date:

2019

Document Version

Peer reviewed version

Link back to DTU Orbit

Citation (APA):

Jensen, P. A., \& van der Voordt, T. (2019). Healthy workplaces: what we know and what else we need to know. Journal of Corporate Real Estate, 22(2), 95-112. https://doi.org/10.1108/JCRE-11-2018-0045

\section{General rights}

Copyright and moral rights for the publications made accessible in the public portal are retained by the authors and/or other copyright owners and it is a condition of accessing publications that users recognise and abide by the legal requirements associated with these rights.

- Users may download and print one copy of any publication from the public portal for the purpose of private study or research.

- You may not further distribute the material or use it for any profit-making activity or commercial gain

- You may freely distribute the URL identifying the publication in the public portal

If you believe that this document breaches copyright please contact us providing details, and we will remove access to the work immediately and investigate your claim. 


\title{
Healthy Workplaces: what we know and what else we need to know
}

\author{
Per Anker Jensen \\ DTU Management Engineering, Technical University of Denmark, \\ Lyngby, Denmark, and \\ Theo van der Voordt \\ Department of Management in the Built Environment, Faculty of Architecture, \\ Delft University of Technology, Delft, The Netherlands and Center for People and \\ Buildings, Delft, The Netherlands
}

\begin{abstract}
Purpose: This paper aims to explore the impact of buildings on the creation of healthy workplaces and end users' physical and mental health and wellbeing. The paper presents available research on the impact of workplace layout, interior design, indoor climate, and "green" offices. It ends with reflections on the main lessons learned, gaps in our current knowledge, and suggestions for further research.

Design/methodology/approach: A literature research has been conducted of all papers in four Corporate Real Estate Management (CREM) and Facilities Management (FM) oriented journals from 2008-2017 that discuss health and wellbeing and related topics such as satisfaction, productivity and creativity.

Findings: A conceptual model to analyse impact factors for healthy workplaces covers the influence of many different variables. Most papers only discuss a particular influencing factor, mainly plants and indoor climate. Various papers show that the spatial layout, in particular the level of openness and opportunities for communication, concentration and privacy, and interior design have an important impact on user satisfaction, perceived productivity support and creativity. These factors may have a positive impact on healthy workplaces as well and can also be benefits of healthy workplaces (HW).

Practical implications: The paper identifies which factors are important to consider for creating healthy workplaces and potential benefits of healthy workplaces.

Originality/value: This paper discusses the role of CREM and FM in creating healthy workplaces and reflects on the available knowledge, current omissions, and the need for transdisciplinary follow-up research.
\end{abstract}

Keywords: health, wellbeing, workplace, spatial layout, interior design, indoor climate

\section{$1 \quad$ Introduction}

The World Health Organization (WHO) defines health as a state of complete physical, mental and social wellbeing, which presents a wider scope than just the absence of disease or infirmity. In the World Book of Happiness 2.0 (Bormans, 2016), physical and mental health are mentioned as important factors to feel happy and to contribute to the quality of life. Public media pay attention to health and wellbeing quite often, by discussing healthy and unhealthy behaviour, stress, burnout, and factors that increase the risk of serious diseases, such as insufficient movement, unhealthy 
eating and drinking behaviour, smoking, and an unhealthy environment with lots of noise, a poor indoor air quality, carbon dioxide emission, fine dust and so on.

From the point of view of Corporate Real Estate Management (CREM) and Facilities Management (FM), a relevant question is, whether appropriate buildings can contribute to people's health and wellbeing and, if so, how and to what extent? Furthermore, related to work, what is needed to create a healthy work environment and to prevent and reduce work fatigue, occupational stress, burn out, and other health problems?

\section{Healthy buildings}

In the healthcare sector, the last three decades show a growing interest in so-called healing environments and healing architecture (e.g. Ulrich et al. 2008; Nickl-Weller and Nickl, 2013). The findings show that outside view (preferably on nature), daylight, and an appropriate indoor climate (natural ventilation, not noisy) all contribute to the healing process of hospital patients.

Regarding healthy buildings in general, an indicator of the growing awareness of the importance of buildings on health and wellbeing is the introduction of the WELL Building Standard ${ }^{\mathrm{TM}}$ in 2015 by The International WELL Building Institute - a public benefit corporation in the US from 2013. The standard sets benchmark measures required to achieve accreditation as a healthy workplace and covers seven aspects: air, water, nourishment, light, fitness, comfort, and mind. The first WELL certified building was the new corporate headquarters of the CREM/FM consultants and service provider CBRE in California. A survey among the staff showed that $94 \%$ expressed a positive effect on their business performance, $92 \%$ mentioned a positive effect on their health and wellbeing, and 83\% felt they were more productive. In a recently WELL-certified office building for the service engineering company Cundall in London, absenteeism was reduced by 50\% compared to the previous office (Wright, 2017).

Muldavin et al. (2017) presents a methodology for assessing the financial performance of health and wellness investments that can be used to analyse property and portfolio decisions. The study applies this methodology to a hypothetical investment in the WELL standard for a 200,000 sq. $\mathrm{ft}$. office building. The paper concludes that proper financial assessment of health and wellness investments can enable dramatic improvements in occupant health and productivity, and provide a strong financial foundation for other energy and sustainability investments.

Healthy workplaces (HW)

The term "Healthy workplaces" has been used widely in research on applied psychology. Grawitch et al. (2006, p 129) write that the notion of "Healthy workplaces" has evolved over the past 60 years: "Beginning in the 1940s, organizations began hosting outings and picnics for their employees. In the 1970s and 1980s, companies provided fitness programs for workers. Now, employees in companies worldwide are inundated with a multitude of organizational programs designed to maximize employee health and the health of organizations." The article was a review of research since 1990 conducted by the American Psychological Association (APA) in relation to its Psychologically Healthy Workplace Award. The aim was to establish an empirical link between workplace practices, employee wellbeing, and organisational improvements, so that psychology can demonstrate its relevance to the development of healthy organisations. However, it is striking that the understanding of HW in the article hardly considers the physical work environment.

As a contrast, "Healthy Workplaces" (HW) is not a term commonly used in scientific literature related to CREM/FM. The first uses we have found was by Bergs (2002) in a paper for a conference on Plants for People. The author refers to the term "Healthy Buildings", which was introduced in 
research on indoor climate as a contrast to Sick Buildings in Sick Building Syndrome. The HW term has also later been used in a limited sense in relation to the effect of living plants in the work environment on staff health and wellbeing (Smith and Pitt, 2011a).

The present paper aims at demonstrating the relevance of CREM/FM to the development of healthy workplaces, people and organisations.

\section{Conceptual framework}

Building on former theoretical frameworks (e.g. De Croon et al., 2005, who focused on healthy work environments; Volker and Van der Voordt, 2005, who focused on employee satisfaction and perceived productivity support; and Batenburg and Van der Voordt, 2008, who searched for the impact of facilities appraisal on perceived productivity support), four workplace characteristics can be assumed to affect employee's health and wellbeing:

1. Characteristics of the physical environment, for instance the office concept (open plan, cellular, activity-based), office-layout (e.g. level of openness), office use (personal desks or shared workspaces), quality of IT infrastructure, interior design, and indoor climate.

2. Organisational characteristics, for instance leadership style, organisational structure, staff and other colleagues, social cohesion, trust, level of competitiveness, future perspective.

3. Job characteristics, for instance work patterns, job demands, supportive tools, personal control, time pressure, stress, and feelings about one's job.

4. Personal characteristics, such as age, gender, education, knowledge and skills, personality, intrinsic motivation, personal attitude to health and healthy behaviour, physical shape (nurture and nature).

In addition, external factors that are not directly related to workplaces, such as personal circumstances, societal values, the labour market, awareness of unhealthy situations, high levels of burn outs and sick leave, and national, local or business programs to promote health and wellbeing, may have an impact as well.

Based on these factors, we have developed the conceptual framework shown in Figure 1. It summarizes the assumed impact factors on healthy workplaces and assumed benefits for the organisation and individuals.

Figure 1 Conceptual framework of influencing factors on healthy workplaces and benefits 


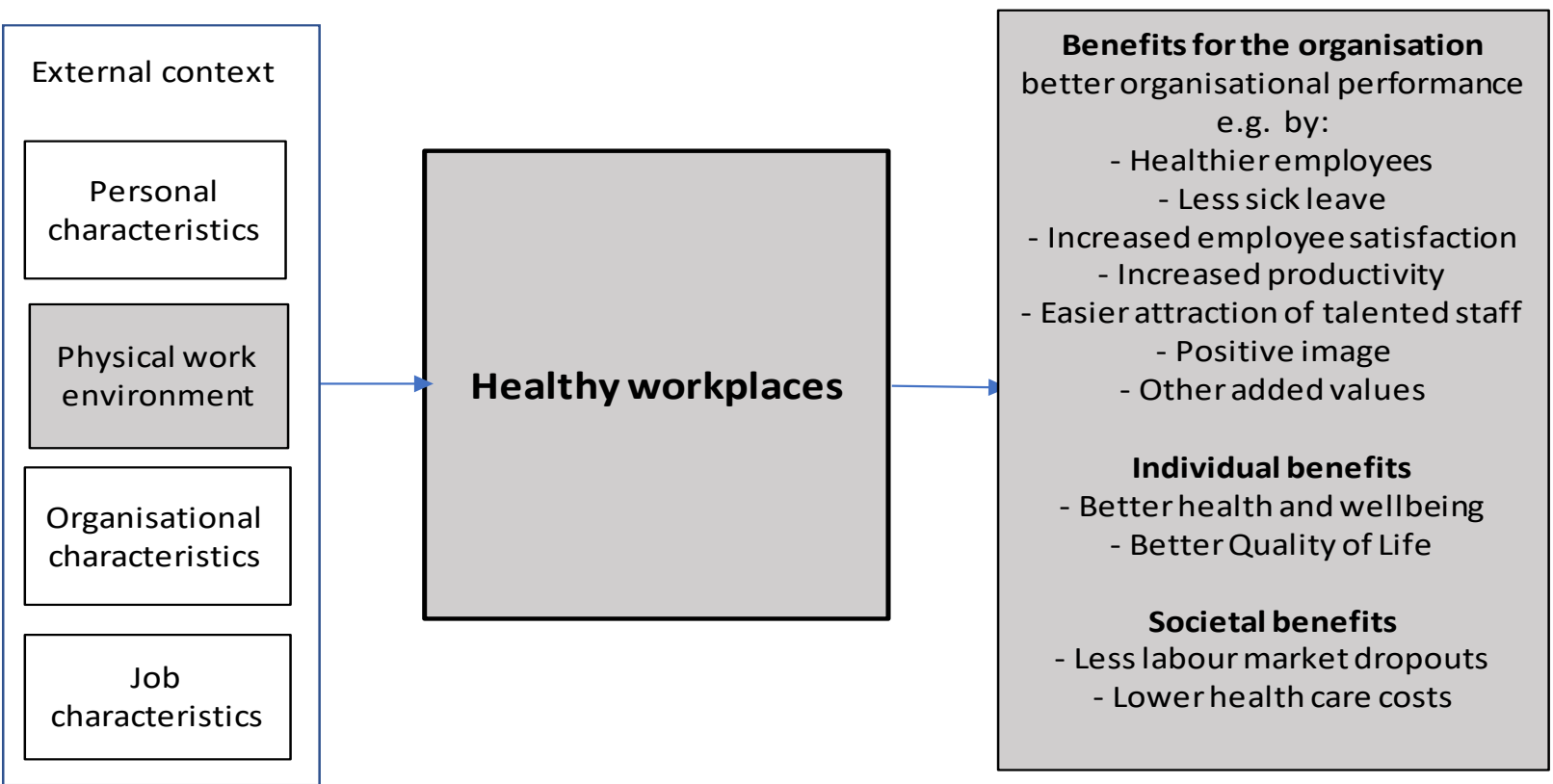

The distinction between output and outcome is in line with Michael Porter's value chain (Porter, 1985) that differentiates between primary and supportive functions, and the Value Adding Management model by Hoendervanger et al. (2017) that makes a distinction between positive impacts and contributions to organisational objectives.

\section{In search of evidence}

The assumed influencing factors can be considered as hypotheses that should be tested. This paper aims to further explore the grey parts of the conceptual model i.e. the impact of the physical work environment on HW, and the impact of HW on potential benefits like increased employee satisfaction, higher productivity and other added values. The leading question is: what research results are available about cause-effect relationships, and what research methods have been used to investigate the impact of various factors on healthy or unhealthy workplaces?

The paper partly builds on a former book chapter of the authors about health and safety in the built environment as one out of twelve added value parameters (Anonymous 1). The book chapter summarized various research findings. For instance, De Croon et al. (2005) based on a review of the literature concluded that not much research is available about the impact of the office location, the office layout, and the office use (fixed versus shared workplaces) on worker health and performance. Out of 1,091 hits, 49 relevant studies were identified and searched for evidence about the impact of these three office dimensions on the office worker's job demands (cognitive workload, working hours), short-term reactions (physiological responses like endocrine and autonomous reactions, and psychological responses such as job satisfaction and stress due to crowding), and long-term reactions on health and performance. The results provide strong evidence that working in open workplaces reduces privacy and job satisfaction. Limited evidence is available that working in open workplaces intensifies cognitive workload and worsens interpersonal relations. A close distance between workstations intensifies cognitive workload and 
reduces privacy. Due to a lack of studies, no evidence was obtained for an effect on long-term reactions. Other papers showed interesting findings as well (e.g. Meijer et al., 2009; Pejtersen et al., 2011; Bodin Danielsson et al., 2014). The findings from this literature search stimulated us to conduct additional literature research for the current paper.

\section{$2 \quad$ Methodology}

The literature review has applied a structured approach according to Webster and Watson (2002), where the review is based on leading journals in the field. We selected the two most important CREM oriented scientific journals and the two most important FM oriented scientific journals, i.e. the Journal of Corporate Real Estate (JCRE), the Corporate Real Estate Journal (CREJ), Facilities, and the Journal of Facilities Management (JFM). We also screened the Workplace Health \& Safety Journal and the International Journal of Workplace Health Management. However, most papers in these journals focus on organisational interventions such as fitness programs, healthy food, weight management, hygiene, pet-friendly workplaces, burnout prevention, health code of conduct, and prevention of bullying and violence.

The review of the four selected CREM/FM journals covered all volumes in the ten-year period 2008 to 2017 . We started by searching for the term "Healthy workplace", but this resulted in very few articles. The two researchers then divided the review between them, so that one researcher, mainly specialised in CREM, screened all articles in the two CREM journals, and the other researcher, mainly specialised in FM, screened all articles in the two FM journals.

The screening was an open search for articles that seemed related to the topic HW based on reading titles, keywords and abstracts as well screening the full text of all articles. The researchers collected a joint database with all articles that seemed relevant and made a summary of all these articles. This resulted in 47 articles of interest. After reading and analysing the 47 papers, a further selection was made of the articles directly related to health and/or wellbeing and leaving out the articles only indirectly related. This reduced the number of papers to the 27 articles, which made up the basis for the detailed review in the present paper. Table 1 presents an overview of the 27 selected papers directly related to health and/or wellbeing in the four CREM/FM journals from 2008 to 2017.

Table 1 CREM/FM papers directly related to health and/or wellbeing

\begin{tabular}{|l|l|l|l|l|l|}
\hline Year & CREJ & JCRE & Facilities & JoFM & Sum \\
\hline 2017 & 2 & 0 & 1 & 1 & 4 \\
\hline 2016 & 0 & 0 & 1 & 0 & 1 \\
\hline 2015 & 1 & 0 & 3 & $2^{*}$ & $6^{*}$ \\
\hline 2014 & 0 & 0 & 0 & 1 & 1 \\
\hline 2013 & 0 & 1 & 2 & 0 & 3 \\
\hline 2012 & 0 & 1 & 0 & 1 & 2 \\
\hline 2011 & 0 & 2 & 2 & 0 & 4 \\
\hline 2010 & 0 & 0 & 1 & 0 & 1 \\
\hline 2009 & - & 3 & 1 & 0 & 4 \\
\hline 2008 & - & 1 & 0 & 0 & 1 \\
\hline $\mathbf{2 0 0 8 - 2 0 1 7}$ & $\mathbf{3}$ & $\mathbf{8}$ & $\mathbf{1 1}$ & $\mathbf{5}$ & $\mathbf{2 7}$ \\
\hline
\end{tabular}

*Incl. 1 editorial article 
Table 2 shows all the 27 articles with information about the country/area the research concerns, the keywords on which the papers were selected, the main topics traced from these papers as well as a short characteristic of the research methods used in the articles (quantitative, qualitative, cases), and where relevant also the number of buildings/cases/locations/offices. Some papers were mainly literature reviews or conceptual papers, but they included reviews of relevant empirical studies and were therefore included.

Table 2 Overview of the papers with country, keywords, main topic and method

\begin{tabular}{|c|c|c|c|c|}
\hline CREJ & Country & Keywords & Topic & Method \\
\hline Muldavin et al. (2017) & USA & Health and wellness & WELL standard & Quan.(ROI modelling) \\
\hline Wright (2017) & UK & $\begin{array}{l}\text { Wellbeing, comfort, } \\
\text { mind }\end{array}$ & $\begin{array}{l}\text { Changing face of } \\
\text { work }\end{array}$ & Conceptual/literature \\
\hline $\begin{array}{l}\text { Alker and Francis } \\
(2015)\end{array}$ & UK & Health and wellbeing & $\begin{array}{l}\text { Health, wellbeing } \\
\text { and productivity }\end{array}$ & Conceptual/literature \\
\hline JCRE & Country & & Topic & Method \\
\hline Feige et al. (2013) & Switzerland & Comfort & Sustainability & Quan., 18 offices \\
\hline Too and Harvey (2012) & Australia & Harmful & Toxic workplaces & Conceptual \\
\hline Smith and Pitt (2011b) & UK & Ill health & $\begin{array}{l}\text { Sustainable } \\
\text { workplaces }\end{array}$ & Conceptual \\
\hline Armitage et al. (2011) & Australia & Self-assessed health & $\begin{array}{l}\text { Green } \\
\text { workplaces }\end{array}$ & Quan., longitudinal \\
\hline Smith and Pitt (2009) & UK & Comfort, health & Plants & Quan., 1 office build. \\
\hline $\begin{array}{l}\text { Brunia and Hartjes- } \\
\text { Gosselink (2009) }\end{array}$ & The Netherlands & Familiar and comfort & Personalisation & Qual., 1 case \\
\hline Kato et al. (2009) & Australia & Self-assessed health & $\begin{array}{l}\text { Green } \\
\text { workplaces }\end{array}$ & Quan., 9 offices \\
\hline $\begin{array}{l}\text { Erlich and Bichard } \\
(2008)\end{array}$ & UK & $\begin{array}{ll}\text { Rest } & \text { and } \\
\text { recuperation. }\end{array}$ & Open plan offices & Qual., various offices \\
\hline Facilities & Country & & Topic & Method \\
\hline Smith et al. (2017) & UK & $\begin{array}{l}\text { Perceived } \\
\text { improvement }\end{array}$ & $\begin{array}{l}\text { Plants and indoor } \\
\text { relative humidity }\end{array}$ & Qual. + quan., 1 case \\
\hline Gou (2016) & Australia, global & Working experience & $\begin{array}{ll}\begin{array}{l}\text { Green } \\
\text { interiors }\end{array} & \text { office } \\
\end{array}$ & Qual. + quan., cases \\
\hline $\begin{array}{l}\text { Maleetipwan-Mattson } \\
\text { and Laike (2015) }\end{array}$ & Sweden & Visual comfort & Lighting & Qual. + quan., 1 case \\
\hline Rasila and Jylhä (2015) & Finland & Social wellbeing. & Noise & Qual., 1 case, 3 loc. \\
\hline $\begin{array}{l}\text { Schlittmeier and Liebl } \\
\text { (2015) }\end{array}$ & Germany & Perceived disturbance & Noise & Quan., 1 case + tests \\
\hline Gou and Lau (2013) & $\begin{array}{l}\text { Hong Kong, } \\
\text { China }\end{array}$ & Comfort & $\begin{array}{l}\text { Thermal } \\
\text { environment }\end{array}$ & Qual. + quan., 1 case \\
\hline Bakker et al. (2013) & The Netherlands & Perceived wellbeing & Colour & Quan., cases \\
\hline Smith et al. (2011) & UK & $\begin{array}{l}\text { Absence, health, } \\
\text { comfort }\end{array}$ & Plants & $\begin{array}{lll}\begin{array}{l}\text { Quan., } \\
\text { building }\end{array} & 1 & \text { office } \\
\end{array}$ \\
\hline Smith and Pitt (2011a) & UK & Reduction in ill health & Plants & $\begin{array}{lll}\begin{array}{l}\text { Quan., } \\
\text { building }\end{array} & 1 & \text { office } \\
\end{array}$ \\
\hline $\begin{array}{l}\text { Bakker and Van der } \\
\text { Voordt (2010) }\end{array}$ & The Netherlands & $\begin{array}{l}\text { Physical, physio- } \\
\text { logical, affective and } \\
\text { cognitive responses }\end{array}$ & Plants & Literature review \\
\hline $\begin{array}{l}\text { Tolman and Parkkila } \\
\text { (2009) }\end{array}$ & Finland & Healthy performance & Moisture & Conceptual \\
\hline JoFM & Country & & Topic & Method \\
\hline
\end{tabular}




\begin{tabular}{|l|l|l|l|l|}
\hline Skogland (2017) & Norway & $\begin{array}{l}\text { The way workplace } \\
\text { was perceived }\end{array}$ & $\begin{array}{l}\text { Activity-based } \\
\text { working }\end{array}$ & Qual., 1 case \\
\hline $\begin{array}{l}\text { Ekstrand and Damman } \\
\text { (2016) }\end{array}$ & Norway & Perceived control & $\begin{array}{l}\text { Frontstage and } \\
\text { backstage }\end{array}$ & Qual., 1 case, 4 loc. \\
\hline $\begin{array}{l}\text { Liynage and Hadjri } \\
\text { (2015) }\end{array}$ & General/editorial & Health and wellbeing & Indoor climate & Conceptual \\
\hline Lo et al. (2014) & China & Less sick time & Sustainability & $\begin{array}{l}\text { Qual. + quan., 12 } \\
\text { build. }\end{array}$ \\
\hline Gou and Lau (2012) & Hong Kong & $\begin{array}{l}\text { Sick building } \\
\text { syndrome symptoms }\end{array}$ & $\begin{array}{l}\text { Sick Building } \\
\text { Syndrome }\end{array}$ & Quan., 30 buildings \\
\hline
\end{tabular}

\section{$3 \quad$ What we found about healthy workplaces}

\subsection{Impact of workplace layout and interior design}

Over the last decades, there has been a strong interest in office layout with the introduction of new office concepts. However, in our search in the four CREM/FM journals of the last ten years there are surprisingly few studies concerning workplace layout and interior design in connection to health and wellbeing, and no papers that studied ergonomics.

Erlich and Bichard (2008) studied to what extent open plan offices match the needs of older knowledge workers. This type of workplaces showed to provide well for collaboration and teamwork activities, but failed to provide an adequate environment for tasks requiring concentration, ways of working that are alternative to the computer, and rest and recuperation.

Brunia and Hartjes-Gosselink (2009) studied personalization in non-territorial offices and found that when objects are prohibited to personalize one's work environment, people seek additional ways to make the environment familiar and comfortable for them and to mark their identity.

Workplace Futures is the name of a Norwegian research programme. Two papers concerning two different case studies were found. A paper by Ekstrand and Damman (2016) concerns a case study of a Norwegian financial institution implementing an Integrated Workplace Strategy (IWS) in four locations. The paper focuses on environmental control understood as the employee's perception of control over customer interaction and work-related demands in three different zones in branch offices: private (backstage), privileged (customer invited access) and public (frontstage). The results show general increased control and satisfaction but with some variation between groups with different types of work.

Skogland (2017) is based on interviews with 65 employees, observations and walkthroughs in a professional service network organisation (auditing, accounting, consulting) 18 months after moving into a new headquarters building and transition to activity-based working. The literature review includes an overview of contradictory findings of the effects of adopting activity-based working in relation to for instance job satisfaction, health and wellbeing, level of distraction and productivity. The paper confirms the need to create a new identity and mindset as a "placeindependent worker” when adopting activity-based working.

Other papers on the impact of office type mainly consider satisfaction and perceived productivity (see section 3.4).

\section{Living plants}

Four papers with A.J. Smith as first author investigate the effect of indoor living plants on office environments. Smith and Pitt (2009) argue that plants are important in removing indoor air 
pollutants and in increasing employee perceptions of wellbeing. Through literature review, the paper identifies plants with the ability to remove common office pollutants. From a perception survey in one office building the paper shows that occupants of planted offices feel more comfortable, productive, healthy and creative and feel less pressure than occupants of non-planted offices. Smith et al. (2011) confirm many of these findings. They also found a substantial reduction in sickness absence in an office area with plants. Both Smith and Pitt (2011a) and Smith et al. (2017) mainly focus on the influence of plants on air humidity. These findings are presented in section 3.2. Smith et al. (2017) also identified a positive impact of plants on work environment aesthetics in an office with plants compared with a control office without plants in the same building. Bakker and Van der Voordt (2010) focused on the impact of plants on productivity but also found positive effects of plants on wellbeing.

\section{Room colours}

Bakker et al. (2013) studied whether red or blue meeting rooms matter in relation to perceived productivity, social cohesion and wellbeing. The data collection was based on questionnaires filled in by participants at the start, the end and a couple of days after a meeting. Seven teams from a Dutch government organisation held seven meetings in meeting rooms with red and blue walls and a reference room with white walls. The findings did not show any significant effects of the red and blue environments on perceived wellbeing, social cohesion and productivity. This is in contrast to statements frequently mentioned in literature. The authors suggest that new ways of testing the impact of colours should be considered.

\subsection{Indoor climate}

All the papers found related to indoor climate concerned a single factor except for an editorial article by Liyanage and Hadjri (2015). Their paper points to the risk that efforts to reduce carbon dioxide emissions may lead to buildings without sufficient ventilation and poor indoor air quality with a negative impact on the health and wellbeing of the occupants. The article concludes that more appropriate strategies are needed to ensure occupants health and wellbeing, e.g. by balancing human comfort and energy consumption during facilities design and post-occupancy stages.

\section{Air humidity}

Tolman and Parkkila (2009) state that aspects of humidity and temperature are the known critical items for condition and healthiness-related performance monitoring of buildings. The paper includes a literature review of humidity and healthy performance. Most referred studies concern housing. They conclude that excessive humidity is a major contributor to adverse health effects both in residential and other indoor spaces.

Smith and Pitt (2011a) and Smith et al. (2017) investigated the effect of indoor living plants on indoor air quality. Both studies were experimental using two UK offices in the same building, one with plants and one as a control. Smith and Pitt (2011a) measured relative humidity, carbon dioxide, carbon monoxide and volatile organic compounds (VOCs). The results showed that relative humidity increased following the introduction of plants and more significantly following additional hydroculture plants being installed. Smith et al. (2017) was based on a case study of an atrium type office building in the southern part of England. The case was selected because the building's FM investigated possible low carbon and sustainable methods of humidification during the winter months. The expected difference in humidification could not be verified, which was explained by cross-contamination. 


\section{Noise}

Two papers concern aspects of noise. Based on many studies, Rasila and Jylhä (2015) conclude that office workers prefer silent and less noisy environments. Office noises may cause stress, tiredness and lack of motivation, but do not increase the number of sick leave days. Their empirical study concerns noise in contact centres in three office locations of a Finnish telecommunication company and looks at noise as a holistic and multidimensional experience of office workers, which can have negative, neutral and positive aspects. Data was collected by interviews. The paper concludes that the perception of the noise environment is closely related to the specific job type and personal traits of individual workers. The same aspects of noise may have both positive and negative consequences for the office workers. The information content of the noise matters a lot.

Schlittmeier and Liebl (2015) presents four empirical studies from Germany. One is a questionnaire survey with 659 respondents in open plan offices in one company exploring the subjective importance of office acoustics and three experimental studies with 20, 30 and 24 participants. The survey showed that acoustics is the subjectively most important workplace factor followed by air quality, temperature, privacy, size of workstation, lighting, and access to windows. Furthermore, irrelevant background speech is the most serious noise problem in open plan offices for employees who are supposed to do silent, concentrated work. The three experimental studies all covered both cognitive performance measured by error rates and disturbance ratings under various acoustic conditions. Other conclusions are that background speech intelligibility and overall noise should be diminished, but care must be taken, so that a room does not become excessively silent.

\section{Lighting}

Maleetipwan-Mattsson and Laike (2015) presents a Swedish case study with tests of six different lighting control systems in an office building with single-occupancy office rooms (cell offices) both in relation to energy consumption and user experience.. The study included 18 offices of each $12-20 \mathrm{~m}^{2}$ at the seventh floor. All rooms had the same type of luminaires (ceiling light) and groups of three rooms had one out of the six control systems installed consisting of different combinations of manual and automatic on/off switching, dimming and time settings. The lighting was tested over one year with field measurements of energy use, light levels and occupancy patterns. The user experiences were investigated by questionnaires filled in by the occupants in the office rooms every second month. The results showed that the use of luminaires varied among the occupants and could be habitual. There were positive potential for manual and daylight dimming with occupancy switch-off controls to increase optimal lighting.

\section{Thermal environment}

Gou and Lau (2013) concerns a Post Occupancy Evaluation (POE) of a certified Green Building in China. The building is from 2008 with 18,000 $\mathrm{m}^{2}$ and serves as a showcase for green design in China. The POE consisted of a questionnaire survey of the occupants and technical measurements of building performance. It had 182 respondents equivalent to a response rate of $73 \%$. The building generally achieved its intended thermal environment of $25^{\circ} \mathrm{C}$ during cool seasons and satisfied more than $80 \%$ of the occupants. Sources of discomfort were areas with low temperatures in both summer and winter.

\section{Sick buildings}

Gou and Lau (2012) present a Sick Building Syndrome (SBS) survey in open-plan offices. The study concerned three design factors: indoor plants, workstation partitions, and operable windows. The indoor environmental characteristics: thermal comfort, air quality, noise and lighting, which 
contribute to SBS symptoms, were also investigated. The study used the Building Use Studies questionnaire like the study by Gou and Lau (2013) and included 30 offices of building-related professionals in Hong Kong with 469 respondents. The results showed that indoor plants and operable windows were related to a reduction of SBS symptoms, while workstation partitions did not affect the incidence of SBS symptoms. There were fewer SBS symptoms reported by the more satisfied respondents.

Toxic workplaces

Too and Harvey (2012) investigate unhealthy workplaces under the name of toxic workplaces, i.e. physical workplaces that are harmful to employees on a day-in and day-out basis. The paper presents a literature review that investigates the links between physical workplace and social behaviour. The sources of toxicity can vary from the physical dimensions of the building, the barriers to free flow of employees, obstacles to face-to-face communications and electronic contact, and lack of personal privacy. Two dysfunctional social behaviours are highlighted: bullying and destructive leadership. The paper presents a logical plan to monitor and remediate the toxic conditions. The findings are synthesised in a framework for understanding the cause of toxicity in the workplace and a self-auditing preventive strategy.

\subsection{Sustainable building}

Several of the papers found concerned sustainability, but with focus on different aspects and using different methods.

\section{Sustainable buildings}

Smith and Pitt (2011b) present a literature review of the role of sustainable buildings in providing healthy workplaces. The paper argues that sustainable construction has focused on environmental sustainability, but this may have contributed to improved health, satisfaction and wellbeing amongst building users. Sick Building Syndrome and poor indoor air are contributory factors to ill health and reduced productivity. The paper suggests that sustainable building practices can reduce these effects.

Feige et al. (2013) investigated the impact of sustainable office buildings on occupant's comfort and self-assessed performance and work engagement. The research consisted of an empirical study of 18 office buildings and is based on survey data from almost 1,500 employees. The study shows that the building itself has a clear impact on the comfort level of the building user. Also, the positive impact of certain features, such as operable windows and the absence of air conditioning, can be clearly identified. While productivity is not directly correlated to comfort levels, work engagement is.

Lo et al. (2014) presents a study of 12 sustainable office buildings and comparisons with conventional office buildings in south China. Data was collected by interviews with property managers and a questionnaire survey among tenants with 76 responses out of more than 400 tenants, who had moved from conventional office buildings into the sustainable office buildings. $44 \%$ of the respondents agreed that workers took less sick leave, while $9 \%$ mentioned more sick leave. The average reduction in days of sick leave was 2.31 per year. The survey also showed that $57 \%$ of the tenants noticed a higher productivity among the employees after moving into the sustainable office buildings, with an average increase of $4.5 \%$ per year. The paper states that the 
increase in productivity and reduction in sick leave in sustainable office buildings confirms the results from other named studies.

Kato et al. (2009) disseminated an online employee survey concerning occupiers' perception of green workplace environment, including questions about satisfaction levels, knowledge of their green workplace environment, functionality, reputation, self-assessed health and productivity impacts, marketing and brand ability, and what they thought of their organisation or employer that had provided such a workplace. The findings suggest that green workplaces offer greater psychological benefits (taking pride of the workplace environment) to occupiers than physical improvements (health and productivity gains). Management perceived greater benefits of green workplace compared to employees.

Certified green buildings

Armitage et al (2011) examines management and employee perceptions of their experiences of working in green workplace environments and assesses the effectiveness of such places. The paper presents results from the second stage of a longitudinal study. It is based on a survey of 31 management and 351 employee respondents occupying Green Building Council Australia Green Star-rated offices for more than 12 months. The results shows that the green workplace is a great place to be, at least most of the time, but there is a discrepancy between the views of management who see greater benefits of the green workplace than their employees.

Gou (2016) focuses on green building certifications for office interiors, which are of particular interests for tenants, who want to improve their corporate environmental impact. The specific focus is LEED for Commercial Interiors (LEED CI), which is compared with three similar systems. The paper is based on an analysis of scorecards for 27 projects from USA, China, Hong Kong, India and Singapore, and focus group interviews with building users from three certified projects. The users were all architects and designers working in architectural companies, who had been involved in retrofitting their own rented space. The relation to healthy workplaces in the certification system is mostly indoor environmental quality, which has a weight of approx. 18\% divided in 17 factors. The users were particular satisfied with improved daylight in the office and improved controllability to adjust workstation lighting. On the other side, they had negative experiences with air quality and unstable temperature, because of the instability in the centralized HVAC system in the host building. The respondents unanimously expressed their needs for shower and fitness facilities, which are seen as important for employees’ health and wellbeing.

\subsection{Potential benefits of $\mathrm{HW}$}

Quality of life

The life quality of people could be an essential measure of healthy buildings, but it is almost impossible to separate the influence of the work environment from the influence of private (and public) life. Nevertheless, Quality Of Life (QOL) is part of a new international standard with FM vocabulary, which defines FM as: "an organizational function which integrates people, place and process within the built environment with the purpose of improving the quality of life of people and the productivity of the core business” (ISO, 2017). QOL is not a topic that has been researched much within CREM/FM. An exception is Rabianski (2007), who presents a survey method that can be used to gather information about the QOL concerns and needs of key employees regarding a new corporate location.

Satisfaction and productivity 
Two of the most frequently researched topics in relation to workplaces are the effects on satisfaction and productivity - mostly measured by level of satisfaction and perceived productivity support using Likert scales. Satisfaction may be regarded as an indicator of wellbeing. Productivity as such is not an expression of a workplace being healthy, but HW can be a precondition for high productivity and performance. As Wright (2017) writes: "It is a genuine recognition that a happy and healthy band of people are more productive and engaged than a disaffected group that do the minimum on a daily basis”. Bergs (2002) also writes about healthy workplaces as productive workplaces and refers to a stream of research on indoor climate from the 1990's, where reduction in productivity is correlated to problems with buildings and health complaints. According to Alker and Francis (2014), the health, wellbeing and productivity agenda is becoming of central importance for the real estate sector. Bakker (2014) states that the reverse relationship is also true: being productive and attaining ones' personal or organisational objectives contributes to satisfaction and wellbeing.

Purdey and Leifer (2012) investigated different types of open plan offices measuring cognitive failures among staff in a local government authority by use of a computer-based instrument. The open plan offices were different regarding layout, workstations and density and classified as either low or high distraction workspaces. The results showed cognitive impairment in the higher distraction work environments, but it was a preliminary study with a small sample size. The authors conclude that it is necessary to differentiate between different sources of distractions and to make objective measurement of the level of noise and other distractions.

Giddings and Ladinski (2016) presents a POE study that focuses on staff satisfaction in connection to implementation of a new workplace strategy in a municipal office building aimed at reducing space and property cost in accordance with UK government policy. The resulting work environment involved a space reduction from $9.11 \mathrm{~m}^{2}$ to $6.96 \mathrm{~m}^{2}$ per workplace. The survey showed that the staff were generally satisfied and had a positive feeling about their new workspace and were not less satisfied because they had less space. The concerns raised were distractions from those seated nearby, not enough privacy, limited personal storage space and dissatisfaction about the limited engagement with choice over the office layout and furniture.

A study by De Been and Beijer (2014) on the impact of office types on satisfaction and perceived productivity support shows that the office type is a significant predictor even though satisfaction with the organisation explains most of the variance. The respondents evaluate productivity support, concentration and privacy highest in individual and shared room offices. People in offices with both open and closed spaces are most satisfied with communication. People in activity-based offices are most satisfied with architecture and layout, but least satisfied with indoor climate. These findings have been confirmed in a cross-case analysis of best practices and worst cases by Brunia et al. (2016).

\section{Creativity}

The relation between HW and creativity was underlined by the CIB W070 Facilities Management conference in 2008 on "Achieving Healthy and Creative Facilities". However, creativity is like productivity not as such an expression of a workplace being healthy, even though workplaces probably have to be healthy to support creativity. A strong pressure to be creative can also be a stress factor and therefore not necessarily healthy (Hoffmann et al., 2012). Four of the papers found in our literature search focus on creative workplaces. 
Martens (2011) summarises the literature from a business management, psychology, environmental psychology and facility management perspective to define creativity, creative process and determinants of creativity, and their relations with the physical workplace. This review reveals knowledge gaps and fragmentation in research about the relation between creativity and the physical workplace. Interviews with creative professionals on their understanding of the creative workplace provide further insight, showing its plurality and complexity.

Kallio et al. (2015) present a longitudinal study of culture and organisational creativity in a regional newspaper company in Finland in connection with a change in physical space. Data was collected before the change in 2007 and nine months after relocation in 2010 and included 15 thematic interviews in both rounds. Organisational creativity is defined as "the creation of a valuable, useful new product, service, procedure or process by individuals working together in a complex social system”. The paper concludes that physical space plays an implicit yet significant role in the emergence of a culture conducive to organisational creativity. Three aspects of organisational culture - openness, equality and collectiveness - were especially affected in a positive way by a new location, new spatial organisation and architectonic details.

Lee (2016) investigates the characteristics of creative workplaces in a study of innovative start-up companies in Michigan, USA, using a content and visual analysis of written and visual images. This led to identification of seven characteristics of the physical work environment critical to the creativity of the workplace. From empirical case studies and a survey among a group of experts, three characteristics were found to be the most important: balanced layout, technology interface for collaboration and spaces for idea generation.

De Paoli and Ropo (2017) conducted a literature review and analysed pictures on the internet. The designs of creative workspaces follow a rather standardized and deterministic assumption of what kind of spaces are considered to produce creativity: open offices, happy, playful communities of close-knit teams and spatial arrangements that resemble home, symbols and memories, sports, technology and nature. According to these authors, this view of creativity and workspaces remains a management fad unless a more balanced approach to the issue is considered.

\section{REFLECTIONS, CONCLUSIONS AND RECOMMENDATIONS}

\subsection{Available evidence for the conceptual framework}

Due to the influence of many factors included in the conceptual model in Figure 1, it is difficult to isolate the impact of the physical environment. Even when focusing on the impacts of the physical environment, the findings from this review confirm the expected influence of many different variables. Different variables can have a positive or negative impact on health and wellbeing. Some variables can have both positive and negative impacts depending on, how they are controlled, and how they are perceived. Measurements of variables in physical terms are not sufficient to make a full evaluation of impact on health and wellbeing. The personal perception by the employees might be just as important. The cause-effect relationships are complex and probably depends both on context, culture and situation, just like research on the usability of workplaces has concluded (Alexander et al. 2013).

In Table 3, the physical aspects with a potential impact on HW have been divided in physical aspects with a possible positive impact, with possible positive or negative impact, and with a possible negative impact. Table 3 also shows examples in alphabetic order for each category and 
with references for each example. The aspect with possible positive impacts are dominated by green and natural elements like daylight, access to fresh air by operable windows, plants and environmental oriented design. There are only few examples with only possible negative impact, but many examples of aspects with possible either positive or negative impacts. 
Table 3 Possible impacts of different physical aspects

\begin{tabular}{|l|l|l|}
\hline Possible impact & Examples & References \\
\hline Positive & Daylight & Gou (2016) \\
& Green office interiors & Gou (2016) \\
& Green workplaces & Armitage et al. (2011), Kato et al. (2009) \\
& Operable windows & Gou and Lau (2012); Feige et al. (2013) \\
& Plants & Bakker and Van der Voordt (2010); Gou and Lau \\
& & (2012); Smith and Pitt (2009); Smith et al. (2017) \\
& Shower and fitness facilities & Gou (2016) \\
& Sustainable buildings & Lo et al. (2014); Smith and Pitt (2011b) \\
\hline Positive or negative & Air humidity & Tolman and Parkkila (2009) \\
& Frontstage vs. backstage & Ekstrand and Damman (2016) \\
& Indoor climate & Lianage and Hadjri (2015) \\
& Lighting & Maleetipwan.Mattson and Like ( 2015) \\
& Noise & Rasila and Jylhä (2015); \\
& & Schlittmeier and Liebl (2015) \\
& Office types & De Been and Beijer (2014) \\
& Space available & Giddings and Ladinski (2016) \\
& Thermal environment & Gou and Lau (2013) \\
\hline \multirow{5}{*}{ Negative } & Air conditioning (central control) & Feige et al. (2013); Gou (2016) \\
& Distractions & Purdy and Leifer (2012) \\
& Sick buildings & Gou and Lau (2012); Smith and Pitt (2011b) \\
& Toxicity & Too and Harvey (2012) \\
\hline \multirow{2}{*}{} &
\end{tabular}

\subsection{Research methods applied in the reviewed papers}

The research methods used in the 27 papers varies a lot as shown in Table 2. 10 papers are quantitative, 7 are conceptual/literature based, 5 are qualitative and the last 5 include a combination of quantitative and qualitative methods. The diversity of methods can be seen as positive from the viewpoint that the topic has been investigated in many different ways and with different angles. It can on the other side also be seen as an expression of the field being immature without a common direction. It can also be seen as positive, that there are several studies combining quantitative and qualitative methods. A comprehensive review on research concerning the added value of FM has shown that research combining such methods often leads to more interesting results than papers using singular methods (Jensen and van der Voordt, 2015).

There is a clear differentiation in the choice of method for different topics. 5 papers concerned generally with office work and workplace layout are all qualitative except one conceptual paper. 6 papers concerned with sustainability are dominantly quantitative (3 papers) or combined quantitative and qualitative ( 2 papers) and one conceptual. Similar goes for 5 papers concerned with plants, where also 3 are quantitative, one is combined and one is conceptual. The remaining 11 papers are for most parts concerned with various other aspects of indoor climate; they represent a wide variety of methods; 4 quantitative, 1 qualitative, 2 combined and 4 conceptual.

\subsection{What else we need to know about Healthy Workplaces}

The amount of research on health and wellbeing in CREM and FM is fairly limited. The four recognized CREM and FM Journals included less than 0.7 paper per journal per year that explicitly regard health and wellbeing. Many topics are only covered in one or a few studies and not always explicitly. Various papers do not discuss health and wellbeing as key topics but just as one of the 
variables in addition to other focus points. It is surprising that in the four CREM/FM journals the potential influence of living plants is one of the most researched topics. Several topics are covered extensively by well-established, specialised research disciplines like indoor climate and ergonomics. However, it is surprising that there is so little research on the influence of workplace layout and design on health and wellbeing, which should be a core field of CREM/FM research.

Most of the reviewed papers do not include specific definitions of the key concepts of healthy workplace, health and wellbeing. In the introduction, we mentioned the definition of health from WHO. Whereas wellbeing includes both physical, mental and emotional facets, there is no general agreement on the best indicators of employee wellbeing (Grawitch et al., 2006). In further research, there is a need to be more clear about the definitions of the key concepts under investigation.

The literature search for this paper was limited to contributions from the field of CREM and FM, presented in four journals in the last ten years, with a focus on the physical work environment. This was a conscious choice to establish a basis for understanding, how the closely connected disciplines of CREM and FM can contribute to create healthy workplaces. By focusing on journals within a specific field, we had the opportunity to study the research in more depth than a broader search of research databases based on a limited number of selected keywords would accommodate. The diversity of the keywords presented for the 27 selected articles in Table 2 clearly demonstrate, that a keyword based search strategy would not have resulted in finding all these articles.

A next step could be to extend this literature search to a longer period of time, to other journals that are relevant for CREM and FM, such as Building Research \& Information, Environment and Behaviour and Applied Ergonomics, and to other sources such as books and conference proceedings. It is promising that at a recent transdisciplinary workplace research conference in Tampere, Finland, seven out of 46 paper presentations had a focus on health and wellbeing. See for instance Groen et al. (2018), who conducted a similar literature review and also found a very limited number of papers on healthy workplaces. Various other presentations discussed related issues such as happiness, vitality, satisfaction, creativity, and flourishing workplaces.

In a follow-up review, additional CREM and FM related topics could be included as well, such as sit-standing desks and other devices to stimulate employees to move, such as desk bikes. Besides, important lessons can be learned from research on health and wellbeing in other types of buildings such as healthcare facilities, schools, laboratories, and residential facilities. It would also be relevant to extend the literature search to journals from other disciplines, in order to test all other parts of the conceptual model.

A meta-analysis of the current knowledge in different disciplines and reflections by experts from different fields such as ergonomics, business administration, human resources management, labour and organisation psychology, and medical sciences may result in a more holistic view and wider evidence. This can be used to further elaborate the current conceptual framework, and to get a deeper understanding of the relationships between health and wellbeing and satisfaction, productivity and creativity. In combination with a more extended literature review that we suggested above, additional empiric research using different research objects, methods and samples, and workshops including both academics, professionals and end users, a growing body of knowledge will become available to make the conceptual framework more precise, complete and evidence-based. 


\section{REFERENCES}

Anonymous (2017) Anonymised for review.

Alexander, K., Blakstad, S.H., Hansen, G.K., Jensen, P.A., Lindahl, G. and Nenonen, N. (2013), "Usability: managing facilities for social outcomes". Proceedings from CIB World Congress, Brisbane, 5-9 May 2013.

Alker, J. and Francis, R. (2014), "Health and productivity: A question of risk?” Corporate Real Estate Journal 4(3), 216-222.

Armitage, L., Murugan, M. and Kato, H. (2011), "Green offices in Australia: a user perception survey", Journal of Corporate Real Estate 13(3), 169-180.

Bakker, I. (2014), Uncovering the secrets of a productive work environment. A journey through the impact of plants and colour, PhD Thesis, Faculty of Industrial Design, TU Delft.

Bakker, I. and Van der Voordt, T. (2010), "The influence of plants on productivity: A critical assessment of research findings and test methods", Facilities 28(9/10), 416-439.

Bakker, I., Van der Voordt, Th., De Boon, J. and Vink, P. (2013), Red or Blue meeting rooms: does it matter? The impact of colour on perceived productivity, social cohesion and wellbeing. Facilities 31(1/2), 68-83.

Batenburg, R. and Van der Voordt, D.J.M. (2008), "Do Facilities Matter? Effects of Facility Satisfaction on Perceived Productivity", Proceedings of the European Facility Management Conference, Manchester, UK, 139-150.

Bergs, J. (2002), "The Effect of Healthy Workplaces on the Well-being and Productivity of Office Workers”. Proceedings of International Plants for People Symposium. Amsterdam.

Bodin Danielsson, C.B., Chungkham, H.S., Wulff, C. and Westerlund, H. (2014), “Office design's impact on sick leave rates”, Ergonomics 57(2), 139-147.

Bormans, L. (2016), Geluk. The world book of Happiness 2.0. Tielt: Lannoo.

Brunia, S. and Hartjes-Gosselink, A. (2009), "Personalization in non-territorial offices: a study of a human need", Journal of Corporate Real Estate 11(3),169-182.

Brunia, S., De Been, I. and Van der Voordt, T. (2016), "Accommodating new ways of working: lessons from best practices and worst cases", Journal of Corporate Real Estate 18(1), 30-47.

De Been, I. and Beijer, M. (2014), "The influence of office type on satisfaction and perceived productivity support", Journal of Facilities Management 12(2), 142-157.

De Croon, E.M., Sluiter, J.K., Paul, P., Kuijer, F.M. and Frings-Dresen, M.H.W. (2005) "The effect of office concepts on worker health and performance: a systematic review of the literature", Ergonomics 48(2), 119-134.

De Paoli, D. and Ropo, A. (2017), "Creative workspaces - a fad or making real impact?", Journal of Corporate Real Estate 19(3), 157-167.

Ekstrand, M. and Damman, S. (2016), "Front and backstage in the workplace: An explorative case study on activity based working and employee perceptions of control over work-related demands.”, Journal of Facilities Management 14(2), 188-202. 
Erlich, A. and Bichard, J.A. (2008), "The Welcoming Workplace: designing for ageing knowledge workers", Journal of Corporate Real Estate 10(4), 273-285.

Feige, A., Wallbaum, H., Janser, M. and Windlinger, L, (2013), "Impact of sustainable office buildings on occupant's comfort and productivity", Journal of Corporate Real Estate 15(1), 7-34.

Giddings, B. and Ladinski, V. (2016), "Implementation of a local authority workspace strategy in the UK: The case of Gateshead Metropolitan Borough Council", Facilities 34(3/4), 196-218.

Grawitch, M.J., Gottschalk, M. and Munz, D.C. (2006), "The Path to a Healthy Workplace”. Consulting Psychology Journal: Practice and Research, 58(3), 129-147

Groen, B.H., Jylhä, T. and Van Sprang, H. (2018), "Healthy office: an evidence based trend in Facility Management?" Paper presented at the Transdisciplinary Workplace Research Conference, Tampere. 19-21 September 2018.

Gou, Z. (2016), "Green building for office interiors: challenges and opportunities", Facilities 34(11/12), 614-629.

Gou, Z. and Lau, S.S-J. (2013), "Post-occupancy evaluation of the thermal environment in a green building", Facilities 31(7/8), 357-371.

Gou, Z. and Lau, S.S-J. (2012), "Sick building syndrome in open-plan offices: Workplace design elements and perceived indoor environmental quality", Journal of Facilities Management 10(4), 256-265.

Hoendervanger, J.G., Bergsma, F., Van der Voordt, T. and Jensen, P.A. (2017), “Tools to manage and measure adding value by FM and CREM", in Jensen, P.A. and van der Voordt, T. (Eds), Facilities Management and Corporate Real Estate Management as Value Drivers: How to Manage and Measure Adding Value, Chapter 17, Routledge, Oxfordshire, 299-322.

Hoffmann, B., Munthe-Kaas, P. and Elle, M. (21012), "Facilitating creative environments". Alexander, K. and Price, I. (2012) (Eds.): Managing organizational ecologies: space, management and organization. Routledge, New York/Oxon, 58-68.

ISO (2017) Facilities management - Vocabulary. International Standard ISO 41011:2017. International Standard Organization.

Jensen, P.A. and van der Voordt, T (2015), How Can FM Create Value to Organisations? - A critical review of papers from EuroFM Research Symposia 2013-2015. Research Report. A EuroFM Publication.

Kallio, T.J., Kallio, K.-M. and Blomberg, A.J. (2015), "Physical space, culture and organisational creativity - a longitudinal study", Facilities 33(5/6), 389-411.

Kato, H., Too, L. and Rask, A. (2009), "Occupier perceptions of green workplace environment: the Australian experience", Journal of Corporate Real Estate 11(3),183-195.

Lee, Y.S. (2016), "Creative workplace characteristics and innovative start-up companies", Facilities 34(7/8), 413-432.

Liyanage, C. and Hadjri, K. (2015), "Achieving zero carbon targets in buildings without compromising health and wellbeing of occupants - a new FM research direction", Journal of Facilities Management 13(3). Editorial. 
Lo, K.K., Hui, E.C.M. and Zhang, K.Z (2014), "The benefits of sustainable office buildings in People's Republic of China (PRC): revelation of tenants and property managers", Journal of Facilities Management 12(4), 337-352.

Martens, Y. (2011),"Creative workplace: instrumental and symbolic support for creativity", Facilities 29(1/2), 63-79.

Maleetipwan-Mattsson, P. and Laike, T. (2015), "Optimal office lighting use: a Swedish case study", Facilities 33(9/10), 573-587.

Meijer, E. M., Frings-Dresen, M. H., and Sluiter, J. (2009), "Effects of Office Innovation on Office Workers' Health and Performance”. Ergonomics 52 (9), 1027-1038.

Muldavin, S., Miers, C.R. and McMackin, K. (2017), "Buildings emerge as drivers of health and profits”, Corporate real Estate Journal 7(22), 177-193.

Nickl-Weller, C. and Nickl, H. (2013), Healing architecture. Salenstein: Braun Publishing.

Pejtersen, J. H.,Feveile, H., Christensen, K.B. and Burr, H. (2011). "Sickness Absence Associated with Shared and Open-Plan Offices - A National Cross Sectional Questionnaire Survey”, Scandinavian Journal of Work, Environment and Health 37 (5), pp. 376-582.

Porter, M.E. (1985), Competitive Advantages: Creating and Sustaining Competitive Performance. Free Press, London.

Purdey, B. and Leifer, D. (2012) "A preliminary study of cognitive failures in open plan offices", Facilities 30(11/12), 472-487.

Rabianski, J.S. (2007) "Employee quality of life in corporate location decisions", Journal of Corporate Real Estate 9(1), 50-64.

Rasila, H. and Jylhä, T. (2015), "The many faces of office noise - case contact center", Facilities 33(7/8), 454-464.

Schlittmeier, S.J. and Liebl, A. (2015), "The effects of intelligible irrelevant background speech in offices - cognitive disturbance, annoyance, and solutions", Facilities 33(1/2), 61-75.

Skogland, M.A.C. (2017), The mindset of activity-based working. Journal of Facilities Management 15(1), 62-75.

Smith, A.J., Fsadni, A. and Holt, G. (2017) "Indoor living plants' effects on an office environment", Facilities 35(9/10), 525-542.

Smith, A.J. and Pitt, M. (2009), "Sustainable workplaces: improving staff health and wellbeing using plants", Journal of Corporate Real Estate 11(1), 52-63.

Smith, A.J. and Pitt, M. (2011a), "Healthy workplaces: plantscaping for indoor environmental quality” Facilities 29(3/4), 169-187.

Smith, A.J, and Pitt, M. (2011b), "Sustainable workplaces and building user comfort and satisfaction", Journal of Corporate Real Estate 13(3), 144-156.

Smith, A., Tucker, T. and Pitt, M. (2011). "Healthy, productive workplaces: towards a case for interior plantscaping", Facilities 29(5/6), 209-223. 
Tolman, A. and Parkkila, T. (2009), "FM tools to ensure healthy performance based buildings", Facilities, 27(11/12), 469-479.

Too, L. and Harvey, M. (2012), "“TOXIC” workplaces: the negative interface between the physical and social environments", Journal of Corporate Real Estate 14(3), 171-181.

Ulrich,, R.S., Zimring, C., Zhu, X., DuBose, J., Seo, H., Choi, Y., Qan, X., and Anjali, J. (2008), "A review of the literature on evidence-based healthcare design.", Health Environments Research \& Design Journal 1(3), 101-165.

Volker, L. and Van der Voordt, D.J.M. (2005), WODI-Evaluation toolkit. Delft: Center for People and Buildings. In Dutch,

Węziak-Białowolska, D., McNeely, E., and VanderWeele, T.J. (2018), “Worker’s Well-Being. Evidence from the Supply Chain in Mexico." Paper presented at the Transdisciplinary Workplace Research Conference, Tampere. 19-21 September 2018.

Webster, J. and Watson, R.T. (2002): “Analyzing the Past to Prepare for the Future: Writing a Literature Review”. Guest Editorial. Mis Quarterly 26(2), xiii-xxiii.

Wright, S. (2017), "What is in the new workplace environment? A consideration of the impact of well-being factors on corporate office provision”. Corporate Real Estate Journal 6(4), 373-383. 